\title{
Recent methods for polygenic analysis of genome-wide data implicate an important effect of common variants on cardiovascular disease risk
}

\author{
Matthew A Simonson ${ }^{1,2,3^{*}}$, Amanda G Wills ${ }^{1,3}$, Matthew C Keller ${ }^{1,3+}$ and Matthew B McQueen ${ }^{2,3+}$
}

\begin{abstract}
Background: Traditional genome-wide association studies are generally limited in their ability explain a large portion of genetic risk for most common diseases. We sought to use both traditional GWAS methods, as well as more recently developed polygenic genome-wide analysis techniques to identify subsets of single-nucleotide polymorphisms (SNPs) that may be involved in risk of cardiovascular disease, as well as estimate the heritability explained by common SNPS.

Methods: Using data from the Framingham SNP Health Association Resource (SHARe), three complimentary methods were applied to examine the genetic factors associated with the Framingham Risk Score, a widely accepted indicator of underlying cardiovascular disease risk. The first method adopted a traditional GWAS approach - independently testing each SNP for association with the Framingham Risk Score. The second two approaches involved polygenic methods with the intention of providing estimates of aggregate genetic risk and heritability.

Results: While no SNPs were independently associated with the Framingham Risk Score based on the results of the traditional GWAS analysis, we were able to identify cardiovascular disease-related SNPs as reported by previous studies. A predictive polygenic analysis was only able to explain approximately $1 \%$ of the genetic variance when predicting the 10-year risk of general cardiovascular disease. However, $20 \%$ to $30 \%$ of the variation in the Framingham Risk Score was explained using a recently developed method that considers the joint effect of all SNPs simultaneously.

Conclusion: The results of this study imply that common SNPs explain a large amount of the variation in the Framingham Risk Score and suggest that future, better-powered genome-wide association studies, possibly informed by knowledge of gene-pathways, will uncover more risk variants that will help to elucidate the genetic architecture of cardiovascular disease.
\end{abstract}

\section{Background}

Cardiovascular disease (CVD), the pathologies associated with the heart and its vascular structure, are a leading cause of death worldwide [1]. Many environmental risk factors exist for the development of CVD, including smoking, hypertension, diabetes, obesity, as well as personality characteristics such as competitiveness and a

\footnotetext{
* Correspondence: masimonson@gmail.com

+ Contributed equally

'Department of Psychology, University of Colorado Boulder, USA

Full list of author information is available at the end of the article
}

Type A behavior pattern[2-4]. Previous studies have also determined that the development of CVD has a strong genetic component, with heritability estimates ranging from $38 \%$ to $57 \%[1,5]$.

Over the past decade, many large-scale efforts have attempted to find genetic factors associated with CVD outcomes using single nucleotide polymorphism (SNP) markers. Several genome-wide association (GWAS) studies have been successful at identifying genetic variants associated with CVD and related phenotypes [6]. However, the effect sizes attributable to these variants have

\section{Ciomed Central}


been small. A sample of previously reported association results and their respective effect size are shown in Table 1. Despite strong statistical evidence, the effect size attributable to any given putative genetic variant is, at best, modest. These results suggest that while GWAS studies have had some success, they currently only explain a very small amount of the genetic risk and heritability for many complex phenotypes, including CVD [7].

The modest number of associated variants found in previous GWAS studies that, together, explain only a small amount of variation in risk likely reflects that a large number of genetic causal variants, each explaining a small amount of risk, contribute to heart disease $[5,8,9]$. We refer to this as the "polygenic theory" of heart disease risk. Recent applications of polygenic approaches to GWAS data have shown substantial improvement in the ability to predict disease risk from common variants [10-12]. In addition, these approaches have improved our ability to assess the degree to which these common variants contribute to the heritability of disease $[10,11]$. These methods of polygenic analysis use all SNPs together to examine the net effect of SNPs on disease risk, including loci of small effect that are typically undetectable (given stringent multiple-testing corrections) with traditional association methods [13]. One approach involves generating a genetic risk score that combines the very small effects of all non-significant alleles that are individually insignificant, but when combined have significant predictive ability. Those subjects with higher genetic risk scores generally have higher risk of disease. Another approach examines the pairwise genetic and phenotypic similarity between subjects in a sample, we then examine if those subjects that have greater genetic similarity also have greater phenotypic similarity to each other than is expected by chance. This second approach estimates heritability due to SNPs by using SNPs to generate a genetic similarity matrix between all individuals in the sample. This is analogous to twin and family methods that estimate heritability based on assumed degrees of relatedness. The advantage of this method over the classic twin study approach is that subjects don't have to be siblings and instead come from a sample of unrelated individuals. Another very important advantage of this method is that family and twin studies rely on assumptions about the causes of similarity between family members (e.g., that genes alone explain the greater similarity of monozygotic over dizygotic twins). This method avoids these assumptions due to the fact that subjects do not come from the same family. Furthermore, the polygenic heritability approach provides information on the frequency spectrum of the causal alleles underlying the phenotype-something that twin and family methods cannot do.

Using three different methods of analysis, we show the extent to which the Framingham Risk Score (an important CVD-related phenotype) can be predicted using common genetic variants, as well as how much variation in the phenotype can be explained overall using GWAS data.

\section{Methods}

\section{GWAS sample}

The study sample for this project was derived from the Framingham SNP Health Association Resource (SHARe), (version 6) as available through NCBI's database of Phenotypes and Genotypes (dbGaP). Information on genotypes (Affymetrix $500 \mathrm{~K}$ ), phenotypes, family structure information, and environmental variables were available in over 9000 participants from three cross-generation enrollment periods.

Table 1 Summary of gene/locus features identified through GWAS in selected previous studies for CVD related phenotypes

\begin{tabular}{|c|c|c|c|c|c|c|c|}
\hline $\begin{array}{l}\text { CVD related } \\
\text { phenotype }\end{array}$ & Region & $\begin{array}{l}\text { Reported gene } \\
\text { (s) }\end{array}$ & $\begin{array}{l}\text { Strongest SNP-risk allele from } \\
\text { study }\end{array}$ & $\begin{array}{l}\text { Risk allele } \\
\text { frequency }\end{array}$ & P-value & Effect size & Reference \\
\hline $\begin{array}{l}\text { Coronary heart } \\
\text { disease }\end{array}$ & 10p11.23 & KIAA1462 & rs3739998-C & 0.44 & $1 \times 10-11$ & $1.15 *[1.11-1.20]$ & {$[42]$} \\
\hline Heart Failure & $15 q 22.31$ & USP3 & rs10519210 & 0.03 & $1 \times 10-8$ & $1.53^{*}[1.05-2.24]$ & [43] \\
\hline $\begin{array}{l}\text { Mortality with heart } \\
\text { failure }\end{array}$ & $3 p 22.2$ & CMTM7 & rs12638540-G & 0.043 & $3 \times 10-7$ & $1.53^{*}[1.01-2.31]$ & [44] \\
\hline $\begin{array}{l}\text { Coronary heart } \\
\text { disease }\end{array}$ & $3 q 22.3$ & MRAS & rs9818870-T & 0.15 & $7 \times 10-13$ & $1.15 *[1.11-1.19]$ & {$[42]$} \\
\hline $\begin{array}{l}\text { Coronary heart } \\
\text { disease }\end{array}$ & $6 q 25.3$ & $\begin{array}{l}\text { SLC22A3, LPAL2, } \\
\text { LPA }\end{array}$ & 4-SNP haplotype-2 & 0.02 & $4 \times 10-15$ & $1.82 *[1.57-2.12]$ & {$[45]$} \\
\hline $\begin{array}{l}\text { Coronary heart } \\
\text { disease }\end{array}$ & $9 p 21.3$ & Intergenic & rs1333049-C & 0.47 & $3 \times 10-19$ & $1.36^{*}[1.27-1.46]$ & {$[46]$} \\
\hline $\begin{array}{l}\text { Coronary heart } \\
\text { disease }\end{array}$ & $9 p 21.3$ & $\begin{array}{l}\text { CDKN2A, } \\
\text { CDKN2B }\end{array}$ & rs1333049-C & 0.47 & $1 \times 10-13$ & $1.47^{*}[1.27-1.70]$ & [7] \\
\hline
\end{tabular}

The genetic effect refers to the OR and [95\% Cl]. All listed values are from [6] 
The Framingham Heart Study (FHS), a project of the National Heart, Lung and Blood Institute (NHLBI), was designed to identify common factors that contribute to risk of cardiovascular disease [14-16]. The FHS has conducted groundbreaking research on CVD outcomes and is cited as the gold standard for cardiovascular genetic epidemiology $[17,18]$. Details on the design and implementation of the FHS can be found elsewhere [19]. Briefly, 14428 individuals from the town of Framingham, Massachusetts, were recruited over the course of three generations. The majority of FHS subjects underwent extensive physical examinations and lifestyle interviews, enabling the collection of genetic data along with highly detailed phenotypic information [19].

\section{Phenotype definition and methods Framingham Risk Score Calculation}

Calculation of the Framingham Risk Score was based on the methods described by D'Agostino et al. (2008). Briefly, D'Agostino et al. (2008) developed a risk score from participants in the Framingham Heart Study to assess CVD (defined as a coronary death, myocardial infarction, coronary insufficiency, angina, ischemic stroke, hemorrhagic stroke, transient ischemic attack, peripheral artery disease, or heart failure) risk within the next 10 years. In the present study, this same method was used to assign risk scores to the current set of participants to be used as the phenotypic endpoint. These scores were calculated for men and women [separately] using the predictors of: (1) age, (2) HDL, (3) total cholesterol, (4) systolic blood pressure, (5) treatment status of systolic blood pressure, (6) smoking status, and (7) diabetic status. See D'Agostino et al. (2008) for a detailed description of the risk score calculation method [20]. The calculated regression coefficients for risk score are presented in table 2 .

Complete details on the available data, including assessment protocols can be found in the Framingham

Table 2 Regression coefficients used in models generating Framingham risk scores for 10-year risk of general cardiovascular disease

\begin{tabular}{lllll}
\hline Men* & & \multicolumn{3}{l}{ Women* } \\
\hline Variable & Beta & p-value & Beta & p-value \\
\hline Log of Age & 3.06117 & $p<.0001$ & 2.32888 & $p<.0001$ \\
Log of Total Cholesterol & 1.1237 & $\mathrm{p}<.0001$ & 1.20904 & $\mathrm{p}<.0001$ \\
Log of HDL Cholesterol & -0.93263 & $\mathrm{p}<.0001$ & -0.70833 & $\mathrm{p}<.0001$ \\
Log of SBP if not treated & 1.933303 & $\mathrm{p}<.0001$ & 2.76157 & $\mathrm{p}<.0001$ \\
Log of SBP if treated & 1.99881 & $\mathrm{p}<.0001$ & 2.82263 & $\mathrm{p}<.0001$ \\
Smoking & 0.65451 & $\mathrm{p}<.0001$ & 0.52873 & $\mathrm{p}<.0001$ \\
Diabetes & 0.57367 & $\mathrm{p}<.0001$ & 0.69154 & $\mathrm{p}<.0001$ \\
\hline
\end{tabular}

The 10 -year risk for women can be calculated as $1-0.95012^{\exp (\Sigma \beta X-26.1931)}$ where Beta is the regression coefficient and $\times$ is the level for each risk factor; the risk for men is given as $1-0.88936^{\exp (\Sigma \beta X-23.9802)}[20]$
SHARe documentation. We note here that blood pressure was measured twice at each examination and the mean of these two measures was used when the participant had both scores. Cholesterol levels were determined by standard enzymatic methods while smoking and hypertensive treatment status was evaluated by participant and physician report. Diabetic status was defined as having definite diabetes (either being treated for diabetes or having a blood sugar reading of greater than or equal to $200 \mathrm{mg} / \mathrm{dL}$ ).

For the original cohort, age, total cholesterol, blood pressure, smoking and diabetic status were assessed at Exam 1. HDL levels were not available for this cohort until Exam 9, making this measure an unusable predictor for risk score of this cohort. Therefore, a mean HDL level of all remaining participants from Exam 9 was calculated and applied to the original cohort individuals in conjunction with their Exam 1 scores. All predictors in the offspring and $3^{\text {rd }}$ generation cohorts were calculated from their first exam. With the exception of missing HDL levels in the original cohort, risk scores were only calculated for individuals with complete predictor information from the first exam.

\section{Genotyping methods and quality control Traditional GWAS and Polygenic Prediction}

Genome-wide genotypes and detailed clinical data on subjects have been made available to researchers through the SHARe (SNP-Health Association Resource) project. Unfiltered genotype data used in our study contained 9236 individuals genotyped for 500,568 SNPs (from the Affymetrix $500 \mathrm{~K}$ mapping array). We used PLINK, the whole genome association analysis toolset, in combination with $\mathrm{R}$ statistical computing software to perform quality control procedures $[10,21]$.

Subjects were excluded if genotyping rates were less than $95 \%$. Individuals were also excluded if the predicted sex based on X-chromosome genotypes did not match the recorded sex. Evidence of non-random genotyping batch effects was inferred from identity-by-missingness (IBM) clustering of subjects. A batch covariate was generated for each subject and used to control for any batch effects. Subjects who were outliers with respect to estimated heterozygosity, those greater than 3 standard deviations from the mean, were excluded. All close relatives of individual subjects, based on mean identity-by-descent (IBD; PIHAT in PLINK) values indicating relatedness of less than $2^{\text {nd }}$ degree relatives, were excluded from the sample. All subjects with an identityby-state (IBS) genetic distance from the sample mean of more than 3 standard deviations were considered outliers with respect to genetic ancestry and were pruned from the sample. This was also confirmed through visual inspection of Multidimensional scaling (MDS) 
plots. Markers were excluded if (1) genotyping rates were less than 95\%, (2) minor allele frequencies were less than 0.01, and (3) if p-values from the Hardy-Weinberg Equilibrium (HWE) test were less than $1 \times 10^{-4}$. Evidence of non-random genotyping failure was examined, as inferred by flanking haplotypic background and significant markers were excluded (PLINK mishap test, $\left.\mathrm{p}<1 \times 10^{-6}\right)$. We also removed individuals who had missing values for any covariates or phenotypic data. After quality controls, the remaining sample consisted of 1772 individuals genotyped on 258891 SNPs.

\section{Polygenic Heritability Analysis}

To minimize the chance that our polygenic heritability findings could be due to confounders (e.g., SNP batch effects) we used additional, very stringent quality control procedures for this analysis, as suggested in [11]. Only those quality control methods that differ from those detailed above are listed below; otherwise all previously mentioned quality control procedures and generation of covariates were the same.

Markers were excluded if p-values from HWE tests were less than .05 . Evidence of non-random genotyping failure was examined, as inferred by flanking haplotypic background and significant markers were excluded (PLINK mishap test, $\mathrm{p}<1 \times 10^{-10}$ )[11]. Subjects were excluded if genotyping rates were less than $99 \%$. All close relatives of individual subjects, based on pairwise IBD (PIHAT) values greater than .025, were excluded from the sample when the GCTA software package was used to estimate heritability. We also removed individuals who had missing values for any covariates or phenotypic data. After quality controls, the remaining sample consisted of 1270 individuals genotyped on 250378 autosomal SNPs.

The polygenic heritability method involves first calculating the pairwise relatedness from SNPs between all individuals in a sample. When using the GCTA software package, any subjects that were related to any other subject with a degree greater than .025 IBD were dropped from the analysis altogether. This resulted in a significant loss of sample size (from 6725 to 1270) and thus a large reduction in power and an increase in standard error of the heritability estimate. To circumvent this large drop in sample size, we utilized an additional method of estimating heritability from pairwise relatedness based on a Haseman-Elston (H-E) regression framework [21]. In a traditional $\mathrm{H}-\mathrm{E}$ regression analysis, genetic relatedness is based on knowledge of pedigree and is regressed on trait difference between twins (either $\mathrm{MZ}$ or DZ). This generates an estimate for how much genetic similarity predicts phenotypic similarity. Our method uses a conceptually similar approach, but instead of using pedigree information, SNPs are used to determine the degree of genetic similarity between unrelated individuals. Using $\mathrm{H}-\mathrm{E}$ regression, only those individual pairwise comparisons $>.025$ IBD (rather than entire subjects) were removed. This allows for the genetic relatedness information from all comparisons between subjects (other than those between close relatives) to be utilized in the analysis. Due to the non-independence between pairwise comparisons (the pairwise relationships from the same person are not independent of one another), we used bootstrapping to determine all significance levels and confidence intervals for $\mathrm{H}$-E regression results. After quality controls, the sample used in the H-E regression analysis consisted of 6725 individuals genotyped on 250378 autosomal SNPs.

\section{Statistical analysis methods}

We performed three methods of genome-wide analysis using population-based methods. For all analyses, a logarithmic transform of the cardiovascular disease phenotype score ensured that outliers in the data did not have unusual leverage on the estimates of our analyses, as well as preventing the assumption of normally distributed errors from being violated [22]. Analysis was also performed on untransformed data and effectively resulted in all of the same conclusions presented.

\section{Traditional GWAS}

Initially a traditional GWAS analysis was performed on all SNPs using Framingham risk score as the target phenotype. Using the PLINK software package (v1.07) with the linear models option, a multiple linear regression test was performed on all quality controlled SNP data using 1772 individuals [10]. An additive mode of inheritance was assumed and empirical p-values were generated for association with the quantitative phenotype at each locus after controlling for age, sex, genotyping batch effects, and (to control for the effects of population stratification) the 20 most significant principal components. A Manhattan plot and a Quantile-Quantile (QQ) plot were used to visualize association results. Prior to the analysis, we adopted the genome-wide significance threshold of $\mathrm{p}<5 \times 10^{-8}$ to account for multiple testing [23]. SNP call intensities were examined to determine whether significant SNPs were aberrations caused by poor quality genotyping. Significant SNPs within single genes based on NCBI Build 36.3 were then examined in Entrez Gene and PubMed to determine if any of these genes had previous associations with phenotypes thought to be related to cardiovascular disease.

\section{Polygenic Prediction}

Our second approach used a predictive polygenic model that effectively estimates the ability of common variants to predict the phenotypic score. Polygenic inheritance is expected to apply to many complex traits, CVD not withstanding [24]. Thousands of small effects that are indistinguishable from background noise when 
performing a traditional GWAS can collectively account for a large proportion of the risk variation. Given the available sample size, we used a 10 fold cross-validation technique to minimize any effects of sampling error on polygenic prediction estimates [25]. Methods of crossvalidation are commonly used when the intent is to estimate how accurately a prediction model will perform with minimal bias due to the sampled data [26]. This method involved partitioning the data from subjects into 10 discovery and test sets respectively. Each discovery set consisted of $90 \%$ of the individuals $(\mathrm{N}=1575)$ from the total data set, while each test set consisted of the remaining $10 \%$ of subjects. Each of the 10 test sets was composed of a different $10 \%$ of the sample, thus no overlap between any of the test sets existed. For each discovery set, a GWAS analysis was performed [27]. Using the results from this discovery phase, subsets of SNPs composed of those with p-values in the ranges of $>.9-1,>.8-.9,>.7-.8,>.6-.7,>.5-.6,>.4-.5,>.3-.4,>$ $.2-.3,>.1-.2,>0-.1$ were generated [13]. The rationale behind grouping subsets of SNPs in ascending 0-.1 pvalue bins is to verify the assumptions of a model where many SNPs of small effect are major contributors to CVD risk. With the current sample size, power to detect variants of small effects is individually very low, and by relaxing significance thresholds, power to detect common variants with small effect sizes increases (with a concomitant rise in number of false associations). SNPs from the discovery set in the lower p-value bins should on average have more predictive ability than those in the higher p-value bins, due to the higher ratio of true associations to type I errors [27].

Using the corresponding independent test set (the remaining $10 \%, \mathrm{~N}=175$ ), a genotypic risk score profile was assigned to each individual that represents the net predictive effect of all reference alleles possessed by a given individual. These genotypic risk scores were calculated using PLINK's SNP scoring routine. Each individual's score was calculated by summing the number of reference alleles at each locus multiplied by the value of the Beta for that respective SNP, which were generated from the initial survey of the discovery set $[10,13,27]$. Linear regression was then used to assess the relationship between risk of cardiovascular disease and the constructed polygenic risk scores in the test group [26]. This same procedure was iterated for each of the 10 sample hold outs, allowing an unbiased estimate (in terms of $r^{2}$ ) of the ability of common SNPs to predict the Framingham Risk Score.

\section{Polygenic Heritability Analysis}

Our third approach used two methods (restricted maximum likelihood and H-E regression) to estimate the proportion of the variance in the Framingham Risk Score that is explained by the common SNPs from the
FHS data set. Instead of trying to predict heart disease risk from genotype, we examined if similarity in phenotype was significantly predicted by similarity of genotype. We examined if those subjects whose genomes are more similar than is expected by chance also have phenotypes that are more similar than is expected by chance. Using the GCTA software package [28], a genetic relationship matrix was generated based on shared combinations of SNPs and weighted by allele frequency. Then a linear model was fit to these genetic relationships using either a) a restricted maximum likelihood (REML) estimation maximization algorithm, as implemented in GCTA, or b) a linear regression model based on a $\mathrm{H}$-E regression framework to estimate the variance explained by common SNPs [28].

\section{Results and Discussion Traditional GWAS}

No individual SNPs were associated with Framingham Risk Score at a genome-wide level of significance after controlling for all covariates. The ten independent SNPs that achieved the lowest p-values (above the significance threshold) are shown in table 3. We further investigated these most significant SNPs to look for any evidence of replication of previous findings. Four of the top ten most significant SNPs were in regions directly associated with CVD or related phenotypes based on previous research. These SNPs are highlighted in table 3.

The SNP rs17051776, located within the gene NBEA has been previously reported to be associated with blood lipid levels [29]. A strong association was found for SNP rs1862523, which is flanking the 5' end of the gene NPR3. NPR3 has been previously reported to be associated with ventricular dysfunction, blood pressure in obesity-associated hypertension [30], as well as a family history of hypertension and cardiovascular disease [31]. The final two SNPs - rs2111202 and rs12611756, are in genes that have been previously reported to be associated with smoking, another factor contributing to Framingham Risk Score [32,33].

\section{Polygenic Prediction}

Two of the ten examined SNP sets (binned by p-values) were able to significantly predict the Framingham Risk Score phenotype, with a third set just missing statistical significance. This suggests a polygenic etiology underlying CVD (as measured via the Framingham Risk Score), as well as the existence of a number of relevant risk variants of small effect across the allele frequency spectrum (see Table 4). While the effect of any single SNP could not be discerned from random noise in the initial GWAS, the combined predictive ability of many SNPs based on score sets provides evidence that some of the risk for CVD is due to common SNPs. The ranges of 
Table 3 Ten most significant SNPs associated with Framingham Risk Score using GWAS

\begin{tabular}{|c|c|c|c|c|c|}
\hline SNP Rank & SNP ID & Region & Gene & Beta & P-value \\
\hline 1 & rs17584191 & $5 q 23.2$ & Intergenic; flanking LMNB1 & 0.09579 & $1.866 \mathrm{e}-05$ \\
\hline 2 & rs17051776 & $13 q 13$ & NBEA & -0.28380 & $2.987 e-05$ \\
\hline 3 & rs483487 & $3 q 26.31$ & NLGN1 & 0.11820 & $3.239 e-05$ \\
\hline 4 & rs215935 & $6 q 14-q 15$ & Intergenic; flanking TBX18 & -0.08192 & $4.258 \mathrm{e}-05$ \\
\hline 5 & rs1862523 & $5 p 14-p 13$ & Intergenic; flanking NPR3 & -0.08753 & $4.610 \mathrm{e}-05$ \\
\hline 6 & rs2111202 & $7 q 3$ & NRCAM & 0.09009 & $5.237 e-05$ \\
\hline 7 & rs12611756 & $2 \mathrm{p} 12-\mathrm{p} 11.1$ & CTNNA2 & 0.08251 & $5.875 e-05$ \\
\hline 8 & rs1491609 & $3 p 13$ & Intergenic; flanking FOXP1 & -0.08143 & 5.952e-05 \\
\hline 9 & rs1346949 & $18 q 21.33$ & Intergenic; flanking PIGN & -0.08592 & $6.730 \mathrm{e}-05$ \\
\hline 10 & rs17205291 & $1 \mathrm{~g} 42$ & Intergenic; flanking KIAA1804 & 0.10680 & $6.860 \mathrm{e}-05$ \\
\hline
\end{tabular}

No single SNP was significant at the genome-wide level after multiple testing correction. SNPs that appear to replicate previous findings are highlighted.

the significantly predictive bins shows the range of pvalues where true associations are maximized relative to the number of type I errors (signal to noise maximization). While a weak overall trend of greater predictive ability is observed as the p-value range of the SNP set becomes more stringent, excessive noise is likely to blame for the apparent lack of this effect in some of the more stringent bins $(>.3-.4,>.1-.2,>0-.1)$. As expected with a sample of this size, the predictive ability of any SNP set is poor, due in large part to the small number of true associations relative to type I errors in the discovery set across allele frequencies. Examination of the Quantile-Quantile (Q-Q) plot from the initial GWAS confirms that few associations diverge from what is expected by chance, explaining both the general uniformity in number of SNPs in each SNP set, as well as the generally weak predictive ability of each set.

\section{Polygenic Heritability Analysis}

A linear model was fit to the CVD data using a restricted maximum likelihood (REML) estimation

Table 4 The number of scoring SNPs that fall into each p-value threshold based on the discovery set is shown.

\begin{tabular}{|c|c|c|c|}
\hline \multicolumn{4}{|c|}{ Target GWAS Statistics for Each Scoring SNP Set } \\
\hline $\begin{array}{l}\text { P-Value Threshold } \\
\text { Range }\end{array}$ & $\begin{array}{l}\text { Number of } \\
\text { SNPs }\end{array}$ & P-Value & $\begin{array}{l}\text { Adjusted } \\
\mathrm{R}^{2}\end{array}$ \\
\hline$>0-.1$ & 24843 & 0.4974 & 0 \\
\hline$>.1-.2$ & 24201 & 0.8096 & 0 \\
\hline$>.2-.3$ & 24329 & $0.00393 *$ & 0.004177 \\
\hline$>.3-.4$ & 23962 & 0.971 & 0 \\
\hline$>.4-.5$ & 24269 & $0.032033^{*}$ & 0.002056 \\
\hline$>.5-.6$ & 24500 & 0.06449 & 0.001383 \\
\hline$>.6-.7$ & 24429 & 0.7129 & 0 \\
\hline$>.7-.8$ & 24429 & 0.23410 & 0.0002382 \\
\hline$>.8-.9$ & 24397 & 0.444 & 0 \\
\hline$>.9-1$ & 24508 & 0.7921 & 0 \\
\hline
\end{tabular}

Significant ranges and their respective $p$-values are highlighted. maximization algorithm to estimate the variance explained by common SNPs. This was done three times using comparable algorithms for REML iterations within the GCTA software package. These REML algorithms included 1.) Average Information, 2.) Fisher-scoring, and 3.) Estimation Maximization; all three resulted in approximately the same genetic variance being explained, with heritability estimates between $31 \%$ and $34 \%$, as is shown in Table 5. However, none of these three estimates were significantly different from zero due to the large standard errors around the estimates. As explained above, the REML analysis used data from only 1270 subjects, limiting the power of this approach.

To utilize more of the data and improve power to detect heritability, we also used a linear regression model based on the H-E regression framework to estimate the variance explained by common SNPs [28]. Heritability due to common SNPs was estimated at $18 \%$. Empirical standard error estimates for genetic variance, phenotypic variance, and $\mathrm{p}$-values were all determined using a bootstrapping re-sampling procedure. Due to the much larger sample size used with the H-E regression algorithm, the estimates provided by this model have much smaller standard error than those provided using the REML approach and give a significant estimate for the heritability of cardiovascular disease due to common SNPs $(\mathrm{p}=.026)$ as can be seen in Table 5.

\section{Conclusions}

The aim of this study was to use recently developed methods of polygenic analysis in conjunction with traditional GWAS methods to identify SNPs that may be involved in the risk of CVD, to understand how well CVD can be predicted from using all SNPs, and to estimate the variance explained in CVD risk when considering all SNPs together. Using data from the FHS, we performed complimentary methods of analysis examining the genetic factors contributing to Framingham Risk Score, a widely accepted indicator of CVD risk. The use 
Table 5 Results of Linear Model analysis using 4 algorithms to estimate heritability $\mathrm{V}(\mathrm{g}) / \mathrm{Vp}$

\begin{tabular}{|c|c|c|c|c|c|c|c|c|c|}
\hline \multirow[b]{2}{*}{ Source } & \multicolumn{2}{|c|}{ Al Algorithm } & \multicolumn{2}{|c|}{ Fisher Algorithm } & \multicolumn{2}{|c|}{ EM Algorithm } & \multicolumn{2}{|c|}{ HE Regression Algorithm } & \multirow[b]{2}{*}{ P-value } \\
\hline & Variance & SE & Variance & SE & Variance & SE & Variance & SE & \\
\hline$\overline{V(g)}$ & 0.000668 & 0.000569 & 0.000668 & 0.000551 & 0.000727 & 0.000552 & 0.250341 & 0.133737 & \\
\hline$\vee p$ & 0.002151 & 0.000087 & 0.002151 & 0.000086 & 0.002152 & 0.000087 & 1.354157 & 0.015038 & \\
\hline$V(g) / p$ & 0.310483 & 0.263126 & 0.310483 & 0.254964 & 0.337865 & 0.25492 & 0.184869 & 0.098453 & $0.026^{*}$ \\
\hline $\log L$ & 3222.103 & & 3222.103 & & 3222.098 & & & & \\
\hline$n$ & 1270 & & 1270 & & 1270 & & 6725 & & \\
\hline
\end{tabular}

Algorithm type and their respective heritability estimates and standard errors are highlighted.

of $\mathrm{H}-\mathrm{E}$ regression in order to maximize sample size in a sample of related individuals and subsequent bootstrapping to estimate heritability and standard errors represents a novel advance that can be utilized in other samples where individuals are highly related $[25,26,28]$.

Due to linkage disequilibrium, genotyped SNPs tag other, unobserved, variants in the genome. Some have argued that when certain SNP appears to be associated with a disease, it is possible that the SNP itself is not the causal variant [34]. The hypothesis that synthetic association, the process described in the previous sentence, represents a significant portion of the common variant associations observed in the literature today, has been shown to be a very unusual occurance [35]. Given synthetic associations are not the driving force behind the majority of disease associated SNPs in the genome, the polygenic methods employed in this paper, used for both estimation of risk and heritability, provides the first evidence that a substantial proportion of the heritability underlying CVD is due to common causal variants. The results of this study show that SNPs predict a small but statistically significant amount of the genetic risk for CVD (as measured via the Framingham Risk Score).

Although our results provide compelling evidence for the polygenic structure of the genetic architecture underlying CVD, it does not pinpoint where these risk variants reside within the human genome. Nevertheless, the top SNPs identified in the initial GWAS performed, and the genes in which they reside, merits further investigation. One way to further inform predictive polygenic analysis would be to include SNPs that lie within genes and pathways when grouping SNPs into predictive SNP sets. Gene and pathway-based prediction would examine the predictive utility of a group of genetic variants that all belong to the same biological pathway [36]. This method of predictive analysis could help to give a more holistic perspective of the underlying structure of CVD and evaluate the contribution of different biological processes and systems to disease risk [37]. Many SNPs that appear to be insignificant when examined independently, or uninformed sets that are weakly predictive of disease state, could be highly significant and predictive when examined as a set composed of SNPs from genes that work in concert within a pathway [38]. An example of the success of pathway based analysis when applied to GWAS is shown by a recent article where the underlying pathways of 11 diseases are examined and strong findings and replication are observed [39].

Given the small effect sizes of common genetic variants, GWAS studies will have to assemble larger sample sizes in order to identify true genetic association signals arising for individual SNPs. For example, Yang et al (2010)[11] conducted a GWAS involving approximately 180,000 subjects where they were able to explain approximately $10 \%$ of the genetic variance in height while simultaneously identifying the significant loci that contribute to this estimate. As sample sizes increase, the power to detect small effects increases. Although the detected polymorphisms may explain little variation individually, with large sample sizes, their cumulative effect should increase, and through pathway analysis and consideration of gene families, such studies can provide important insight into the genetic architecture underlying traits. Similar conclusions have been drawn from recent studies involving the polygenic structure of height as well as schizophrenia $[10,11]$.

One of the weaknesses of the present study was the modest sample sizes (see table 5) used for the GWAS, the polygenic risk score analysis, and the estimation of heritability using the maximum likelihood approach. As explained above, larger sample sizes than the one currently used are needed to detect small effects sizes likely to underlie the genetic variation in CVD. Similarly, it is likely that the ability to predict CVD using SNPs will improve measurably with larger sample sizes, as recently shown to be the case in schizophrenia [10]. The ability to predict a significant portion of disease risk from genotype can result in early intervention and improved treatment. Identification of a molecular profile could be a useful tool for prevention and management of CVD and related disorders [40].

CVD is a complex, highly polygenic disease that is one of the leading causes of death worldwide. This study has demonstrated novel approaches to investigate heritability due to SNPs in samples where individuals are unrelated and has also shown that SNPs can be used to predict 
CVD. We also provide evidence strongly consistent with the polygenic theory of CVD and show that much of the genetic variation underlying CVD is likely to be due to common causal polymorphisms. Based on these results, we conclude that there remains much information in, and much to be learned by the continued use of SNP panels in the investigation of cardiovascular phenotypes as well as other human diseases. Through the use of these methods in future studies, a better understanding of disease, and improved clinical outcomes are achievable [41].

\section{Acknowledgements and Funding}

Contribution by MAS was partially supported by two institutional training grants from the National Institute of Child Health and Human Development (T32 HD007289, Michael C. Stallings, Director) and the National Institute of Mental Health (T32 MH016880, John K. Hewitt, Director). AGW was partially supported by two institutional training grants from the National Institute of Child Health and Human Development (T32 HD007289, Michael C. Stallings, Director) and the National Institute on Drug Abuse (T32 DA017637, John K. Hewitt). Contribution by MCK was supported by a grant from the National Institutes of Health and the National Institute of Mental Health (Bethesda, MD, USA; grant MH085812). Contribution by MBQ was supported by a grant from National Institute of Mental Health (grant MH063445).

The Data used in this study is from the Framingham Heart Study of the National Heart Lung and Blood Institute of the National Institutes of Health and Boston University School of Medicine. This work was supported by the National Heart, Lung and Blood Institute's Framingham Heart Study (Contract No.N01-HC-25195). The datasets used for the analyses described in this manuscript were obtained from the database of genotype and phenotype (dbGaP) found at http://www.ncbi.nlm.nih.gov/gap through dbGaP accession number phs000007.v6.p3. This manuscript was not prepared in collaboration with investigators of the Framingham Heart Study and does not necessarily reflect the opinions or views of the Framingham Heart Study, Boston University, or the NHLBI. Samples and associated phenotype data were produced as part of NHLBI's SNP Health Association Resource (SHARe) project.

\section{Author details}

'Department of Psychology, University of Colorado Boulder, USA.

${ }^{2}$ Department of Integrative Physiology, University of Colorado Boulder, USA. ${ }^{3}$ Institute for Behavioral Genetics, University of Colorado at Boulder, Boulder, CO 80303, USA.

\section{Authors' contributions}

MS and AW carried out all statistical analyses and pre-analysis organization of data. MS wrote all custom software used during the analysis and was the primary author of manuscript. MK and MM consulted with MS on appropriate statistical and genetic analysis methods to employ, and were directly involved in organizing the structure and revision of the manuscript. All authors have read and approved the final manuscript.

Received: 16 July 2011 Accepted: 26 October 2011

Published: 26 October 2011

\section{References}

1. Zdravkovic S, Wienke A, Pedersen NL, Marenberg ME, Yashin Al, De Faire U: Heritability of death from coronary heart disease: a 36-year follow-up of 20966 Swedish twins. J Intern Med 2002, 252(3):247-254.

2. McCann SJ: Younger achievement age predicts shorter life for governors: testing the precocity-longevity hypothesis with artifact controls. Pers SoC Psychol Bull 2003, 29(2):164-169.

3. Rhodewalt F, Smith TW: Handbook of social and clinical psychology: The health perspective.Edited by: Snyder CR, Forsyth DR. Elmsford, NY, US: Pergamon Press; 1991:162:197-220.
4. Boon NA, Colledge NR, Walker BR, Hunter JAA: Davidson's Principles \& Practice of Medicine. Philadelphia: Churchill Livingstone Elsevier; 2006.

5. Arking DE, Chakravarti A: Understanding cardiovascular disease through the lens of genome-wide association studies. Trends Genet 2009, 25(9):387-394.

6. A Catalog of Published Genome-Wide Association Studies. [http://www genome.gov/gwastudies].

7. Burton PR, Clayton DG, Cardon LR, Craddock N, Deloukas P, Duncanson A, Kwiatkowski DP, McCarthy MI, Ouwehand WH, Samani NJ, Todd JA, Donnelly P, Barrett JC, Davison D, Easton D, Evans D, Leung HT, Marchini JL, Morris AP, Spencer CCA, Tobin MD, Attwood AP, Boorman JP, Cant B, Everson U, Hussey JM, Jolley JD, Knight AS, Koch K, Meech E, et al: Genome-wide association study of 14,000 cases of seven common diseases and 3,000 shared controls. Nature 2007, 447(7145):661-678.

8. Collins FS, Guyer MS, Charkravarti A: Variations on a theme: cataloging human DNA sequence variation. Science 1997, 278(5343):1580-1581.

9. Risch N, Merikangas K: The future of genetic studies of complex human diseases. Science 1996, 273(5281):1516-1517.

10. Purcell S, Neale B, Todd-Brown K, Thomas L, Ferreira MA, Bender D, Maller J, Sklar P, de Bakker PI, Daly MJ, Sham PC: PLINK: a tool set for wholegenome association and population-based linkage analyses. Am J Hum Genet 2007, 81(3):559-575.

11. Yang J, Benyamin B, McEvoy BP, Gordon S, Henders AK, Nyholt DR, Madden PA, Heath AC, Martin NG, Montgomery GW, Goddard ME, Visscher PM: Common SNPs explain a large proportion of the heritability for human height. Nat Genet 2010, 42(7):565-569.

12. Manolio TA, Collins FS, Cox NJ, Goldstein DB, Hindorff LA, Hunter DJ, McCarthy MI, Ramos EM, Cardon LR, Chakravarti A, Cho JH, Guttmacher AE, Kong A, Kruglyak L, Mardis E, Rotimi CN, Slatkin M, Valle D, Whittemore AS, Boehnke M, Clark AG, Eichler EE, Gibson G, Haines JL, Mackay TF, McCarroll SA, Visscher PM: Finding the missing heritability of complex diseases. Nature 2009, 461(7265):747-753.

13. International Multiple Sclerosis Genetics C, Bush WS, Sawcer SJ, de Jager PL, Oksenberg JR, McCauley JL, Pericak-Vance MA, Haines JL: Evidence for polygenic susceptibility to multiple sclerosis-the shape of things to come. Am J Hum Genet 2010, 86(4):621-625.

14. Dawber TR, Meadors GF, Moore FE Jr: Epidemiological approaches to heart disease: the Framingham Study. Am J Public Health Nations Health 1951, 41(3):279-281.

15. Feinleib M, Kannel WB, Garrison RJ, McNamara PM, Castelli WP: The Framingham Offspring Study. Design and preliminary data. Prev Med 1975, 4(4):518-525.

16. Splansky GL, Corey D, Yang Q, Atwood LD, Cupples LA, Benjamin EJ, D'Agostino RB Sr, Fox CS, Larson MG, Murabito JM, O'Donnell CJ, Vasan RS, Wolf PA, Levy D: The Third Generation Cohort of the National Heart, Lung, and Blood Institute's Framingham Heart Study: design, recruitment, and initial examination. Am J Epidemiol 2007, 165(11):1328-1335

17. Dawber TR, Moore FE, Mann GV: Coronary heart disease in the Framingham study. Am J Public Health Nations Health 1957, 47(4 Pt 2):4-24.

18. Jaquish CE: The Framingham Heart Study, on its way to becoming the gold standard for Cardiovascular Genetic Epidemiology? BMC Med Genet 2007, 8:63.

19. About FHS. In The Framingham Heart Study. [http://www. framinghamheartstudy.org/about/index.html].

20. D'Agostino RB, Vasan RS, Pencina MJ, Wolf PA, Cobain M, Massaro JM, Kannel WB: General cardiovascular risk profile for use in primary care: The Framingham heart study. Circulation 2008, 118(4):E86-E86.

21. Team RDC: R: A language and environment for statistical computing. Vienna, Austria: R Foundation for Statistical Computing; 2008.

22. Balding DJ: A tutorial on statistical methods for population association studies. Nat Rev Genet 2006, 7(10):781-791.

23. Duggal P, Gillanders EM, Holmes TN, Bailey-Wilson JE: Establishing an adjusted $p$-value threshold to control the family-wide type 1 error in genome wide association studies. BMC Genomics 2008, 9:516.

24. Gottesman II, Shields J: A polygenic theory of schizophrenia. Proc Natl Acad Sci USA 1967, 58(1):199-205.

25. Kohavi R: A study of cross-validation and bootstrap for accuracy estimation and model selection. Proceedings of the Fourteenth International 
Joint Conference on Artificial Intelligence: 1995 San Francisco, CA; 1995, 1137-1143.

26. Picard R, Cook D: Cross-Validation of Regression Models. Journal of the American Statistical Association 1984, 79(387):575-583.

27. International Schizophrenia C, Purcell SM, Wray NR, Stone JL, Visscher PM, O'Donovan MC, Sullivan PF, Sklar P: Common polygenic variation contributes to risk of schizophrenia and bipolar disorder. Nature 2009, 460(7256):748-752

28. Yang J, Lee SH, Goddard ME, Visscher PM: GCTA: a tool for genome-wide complex trait analysis. Am J Hum Genet 2011, 88(1):76-82.

29. Talmud PJ, Drenos F, Shah S, Shah T, Palmen J, Verzilli C, Gaunt TR, Pallas J, Lovering R, Li K, Casas JP, Sofat R, Kumari M, Rodriguez S, Johnson T, Newhouse SJ, Dominiczak A, Samani NJ, Caulfield M, Sever P, Stanton A, Shields DC, Padmanabhan S, Melander O, Hastie C, Delles C, Ebrahim S, Marmot MG, Smith GD, Lawlor DA, et al: Gene-centric association signals for lipids and apolipoproteins identified via the HumanCVD BeadChip. Am J Hum Genet 2009, 85(5):628-642.

30. Fox AA, Collard CD, Shernan SK, Seidman CE, Seidman JG, Liu KY, Muehlschlegel JD, Perry TE, Aranki SF, Lange C, Herman DS, Meitinger T, Lichtner P, Body SC: Natriuretic peptide system gene variants are associated with ventricular dysfunction after coronary artery bypass grafting. Anesthesiology 2009, 110(4):738-747.

31. Aoi N, Soma M, Nakayama $T$, Rahmutula D, Kosuge $K$, Izumi $Y$, Matsumoto K: Variable number of tandem repeat of the $5^{\prime}$-flanking region of type- $C$ human natriuretic peptide receptor gene influences blood pressure levels in obesity-associated hypertension. Hypertens Res 2004, 27(10):711-716.

32. Ishiguro $H$, Liu QR, Gong JP, Hall FS, Ujike $H$, Morales M, Sakurai T, Grumet M, Uhl GR: NrCAM in addiction vulnerability: positional cloning, drug-regulation, haplotype-specific expression, and altered drug reward in knockout mice. Neuropsychopharmacology 2006, 31(3):572-584.

33. Mexal S, Berger R, Pearce L, Barton A, Logel J, Adams CE, Ross RG Freedman R, Leonard S: Regulation of a novel alphaN-catenin splice variant in schizophrenic smokers. Am J Med Genet B Neuropsychiatr Genet 2008, 147B(6):759-768.

34. Dickson SP, Wang K, Krantz I, Hakonarson H, Goldstein DB: Rare variants create synthetic genome-wide associations. PLoS Biol 2010, 8(1):e1000294.

35. Anderson CA, Soranzo N, Zeggini E, Barrett JC: Synthetic associations are unlikely to account for many common disease genome-wide association signals. PLOS Biol 2011, 9(1):e1000580.

36. Wang K, Li M, Bucan M: Pathway-based approaches for analysis of genomewide association studies. Am J Hum Genet 2007, 81(6):1278-1283.

37. Curtis RK, Oresic M, Vidal-Puig A: Pathways to the analysis of microarray data. Trends Biotechnol 2005, 23(8):429-435.

38. Lesnick TG, Papapetropoulos S, Mash DC, Ffrench-Mullen J, Shehadeh L, de Andrade M, Henley JR, Rocca WA, Ahlskog JE, Maraganore DM: A genomic pathway approach to a complex disease: axon guidance and Parkinson disease. PLoS Genet 2007, 3(6):e98.

39. Peng G, Luo L, Siu H, Zhu Y, Hu P, Hong S, Zhao J, Zhou X, Reveille JD, Jin L, Amos Cl, Xiong M: Gene and pathway-based second-wave analysis of genome-wide association studies. Eur J Hum Genet 2010, 18(1):111-117.

40. Clark AG, Boerwinkle $E$, Hixson J, Sing CF: Determinants of the success of whole-genome association testing. Genome Res 2005, 15(11):1463-1467.

41. O'Hara B, Komulainen P, Savolainen O, Sillanpää MJ: A Latent Variable Approach to Multivariate Quantitative Trait Loci. Nature Proceedings 2010, 10101(07 January 2010):4137.

42. Erdmann J, Grosshennig A, Braund PS, Konig IR, Hengstenberg C, Hall AS, Linsel-Nitschke P, Kathiresan S, Wright B, Tregouet DA, Cambien F, Bruse P, Aherrahrou Z, Wagner AK, Stark K, Schwartz SM, Salomaa V, Elosua R, Melander O, Voight BF, O'Donnell CJ, Peltonen L, Siscovick DS, Altshuler D, Merlini PA, Peyvandi F, Bernardinelli L, Ardissino D, Schillert A, Blankenberg $S$, et al: New susceptibility locus for coronary artery disease on chromosome 3q22.3. Nat Genet 2009, 41(3):280-282.

43. Smith NL, Felix JF, Morrison AC, Demissie S, Glazer NL, Loehr LR, Cupples LA, Dehghan A, Lumley T, Rosamond WD, Lieb W, Rivadeneira F, Bis JC, Folsom AR, Benjamin E, Aulchenko YS, Haritunians T, Couper D, Murabito J, Wang YA, Stricker BH, Gottdiener JS, Chang PP, Wang TJ, Rice KM, Hofman A, Heckbert SR, Fox ER, O'Donnell CJ, Uitterlinden AG, et al: Association of genome-wide variation with the risk of incident heart failure in adults of European and African ancestry: a prospective meta-analysis from the cohorts for heart and aging research in genomic epidemiology (CHARGE) consortium. Circ Cardiovasc Genet 2010, 3(3):256-266

44. Morrison AC, Felix JF, Cupples LA, Glazer NL, Loehr LR, Dehghan A, Demissie S, Bis JC, Rosamond WD, Aulchenko YS, Wang YA, Haritunians T, Folsom AR, Rivadeneira F, Benjamin EJ, Lumley T, Couper D, Stricker BH, O'Donnell CJ, Rice KM, Chang PP, Hofman A, Levy D, Rotter Jl, Fox ER, Uitterlinden AG, Wang TJ, Psaty BM, Willerson JT, van Duijn CM, et al: Genomic Variation Associated With Mortality Among Adults of European and African Ancestry With Heart Failure The Cohorts for Heart and Aging Research in Genomic Epidemiology Consortium. Circ-Cardiovasc Gene 2010, 3(3):248-U264.

45. Tregouet DA, Konig IR, Erdmann J, Munteanu A, Braund PS, Hall AS, Grosshennig A, Linsel-Nitschke P, Perret C, DeSuremain M, Meitinger T, Wright BJ, Preuss M, Balmforth AJ, Ball SG, Meisinger C, Germain C, Evans A, Arveiler D, Luc G, Ruidavets JB, Morrison C, van der Harst P, Schreiber S, Neureuther K, Schafer A, Bugert P, El Mokhtari NE, Schrezenmeir J, Stark K, et al: Genome-wide haplotype association study identifies the SLC22A3LPAL2-LPA gene cluster as a risk locus for coronary artery disease. Nature Genetics 2009, 41(3):283-285

46. Samani NJ, Erdmann J, Hall AS, Hengstenberg C, Mangino M, Mayer B, Dixon RJ, Meitinger T, Braund P, Wichmann HE, Barrett JH, Konig IR, Stevens SE, Szymczak S, Tregouet D, lles MM, Pahlke F, Pollard H, Lieb W, Cambien F, Fischer M, Ouwehand W, Blankenberg S, Balmforth AJ, Baessler A, Ball SG, Strom TM, Braenne I, Gieger C, Deloukas P, et al: Genomewide association analysis of coronary artery disease. New Engl J Med 2007, 357(5):443-453.

\section{Pre-publication history}

The pre-publication history for this paper can be accessed here: http://www.biomedcentral.com/1471-2350/12/146/prepub

doi:10.1186/1471-2350-12-146

Cite this article as: Simonson et al:: Recent methods for polygenic analysis of genome-wide data implicate an important effect of common variants on cardiovascular disease risk. BMC Medical Genetics 2011 12:146.

\section{Submit your next manuscript to BioMed Central and take full advantage of:}

- Convenient online submission

- Thorough peer review

- No space constraints or color figure charges

- Immediate publication on acceptance

- Inclusion in PubMed, CAS, Scopus and Google Scholar

- Research which is freely available for redistribution

Submit your manuscript at www.biomedcentral.com/submit
C) Biomed Central 